\title{
LEGACY COLLECTIONS, THEIR VALUE AND THEIR ACCESSIBILITY
}

Grace Koch, Visiting Senior Research Fellow, Australian National University, Canberra, Australia

\section{Introduction}

In this article, I want to explore some of the meanings of the word, legacy, in relation to archives management and will discuss some of the possible problems raised by legacy collections. I will then move on to the extra issues that Indigenous legacy collections can raise, with some case studies from the archive I know best- AIATSIS. Finally, I would like to examine how some Australian collecting organisations are handling Indigenous collections, including legacy ones, and will move on to some funding initiatives that are targeted to legacy material. My paper focuses upon audiovisual material only, but some examples will include references to other media.

This research was supported under Australian Research Council's Linkage Program. Grant no. LPI30I0I3I, Return, Reconcile, Renew: understanding the history, effects, and opportunities of repatriation and building an evidence base for the future.

\section{What are legacy collections?}

First of all, what do I mean by the term, legacy? Generally, a legacy is something handed down from one person to another. This can mean an inheritance, personal histories, or in the case of archives, we can use the term to describe the bulk of many of our collections. Some collections may actually contain the word in their titles, such as the Toscanini Legacy Collection of sound recordings that were willed to the New York Public Library², or Legacy, a compilation of recordings published by the $\mathrm{BBC}$ consisting of oral histories of people affected by the Troubles in Northern Ireland.

In a technical sense, legacy can also be used to describe outdated or obsolete formats, either as carriers of information such as reel-to-reel tapes or as computer systems and software.

Of course, not all legacy collections are problematic; in many cases they have been carefully documented and preserved. Those are not the focus of this article. I want to examine collections that pose special difficulties in managing them, and would like to propose the following definition of problematic legacy collections.

Collections, often created long ago, deposited in the past with varying degrees of documentation, that may have been deposited under ambiguous or restricted access conditions that make them difficult for archives to manage.

Such collections often appear in backlogs because they take much time and effort to be properly processed. Thus, these collections are in danger of being lost simply because they are just too hard to manage. Most appear in catalogues, but difficulties arise when a client wants to see or hear them.

2 https://nypl.bibliocommons.com/item/show/II I59921052907 the toscanini legacy collection of sound recordings. 


\section{Difficulties in general with management of legacy collections}

Management difficulties arise because:

- The original depositor may not be known or contact information may have been lost. This problem may not arise until someone wants to access a collection that is seldom used. Special problems arise if the depositor had stated that he or she must be contacted before the collection can be accessed and if he/she cannot be located.

- Provisions in access contracts have changed, but the original conditions have not been updated. The pressure upon collecting institutions to disseminate their holdings by funding bodies can spell disaster for a collection if it has stringent access conditions. Is it worth preserving if it can't be used?

- Cataloguing practices may have changed, and earlier records may not have been updated for the legacy collection because of difficulties in managing it. Greene and Meissner argue that the failure to process collections holds back research, leads to duplicates being purchased, and makes them more vulnerable to being stolen or lost because libraries and archives don't know what they have. (Greene and Meissner 2005:2II)

- In a jointly-authored report surveying how many collections of sound recordings require digitization in the US, it was found that material requiring specialized workflow cost twice as much to digitize. (Lyons et al 2015: I8) If part of this specialized workflow includes documentation and/or revisiting access conditions, the collection may not be digitized due to cost restraints and is in danger of being lost.

With external pressure upon archives to make their holdings available, legacy collections may be very time-consuming to manage. They need to be assessed according to their value and condition, and handled accordingly. Risk management processes are required to manage them until the final choice is made whether or not to keep them as part of the collections.

\section{Legacy collections of indigenous materials}

Management of audiovisual collections that document the cultural practices of the original people of a region can be very complex. I shall use the term, Indigenous, for this type of material. Contents of such collections may include ceremony, song, narratives, genealogies, or language elicitation. In Australia, research archives, small Indigenous organizations, Indigenous broadcasting organizations, regional archives, and special collections within larger libraries and archives hold most of this type of material. ${ }^{3}$

There are varying degrees of access conditions placed upon such collections. Janet ToppFargion and Paulina Proutskova (2008) described some of the reasons that ethnomusicologists place restrictions on their material, some of which overlap my earlier points:

- Some collectors who went through great difficulties in getting their recordings want to maintain close control of their collections.

- The collectors want to protect the confidentiality of the people and the groups that they study.

- Proprietary rights may not be clear; the actual ownership of the material may not be known or there may not be contact details for the owner.

- Some collectors may not have documented their recordings to a standard required of the archive with whom they place their material because it would take too much work.

- There may be gender-restricted or ceremonially-restricted content that could cause distress to Indigenous people. (Proutskova and Topp-Fargion 2008: 49)

The fact remains, though, that archives with collections that were gathered many years ago may find that documentation and access conditions make them very difficult to manage. As they

3 See Laszlo, Kristina 2005 for a discussion of issues raised by First Nations material in archives. 
exist in the 'too hard basket', they are in danger of being overlooked in digitization priorities, thus risking being lost.

\section{Events in Australia highlighting legacy collections}

Several events within the past few decades have contributed towards the growing interest for Indigenous people to interrogate archival collections.

\section{I The Aboriginal Land Rights (Northern Territory) Act (Cth) I976 (ALRA) and the Native Title Act 1993 (Cth) (NTA).}

Both of these Acts passed by the Federal Australian Parliament created a set of procedures whereby Indigenous people in Australia could prove their rights to their traditional land and gain ownership.

The ALRA covered only the Northern Territory of Australia. Successful claims resulted in the strongest recognized title that exists for land ownership known as inalienable Aboriginal freehold. The traditional owners proved their rights to the land under claim by performing or describing ceremonies, giving detailed genealogies for the owners, and submitting many oral histories. Archival holdings of early recordings, photographs and films that were relevant to the claim group or geographical area could also serve as evidence. Aboriginal claimants requested copies of hundreds of print and audiovisual materials to strengthen their claims, and archivists' workloads increased in order to supply the items. Still, the request load was manageable within existing staffing levels.

A dramatic shift in requests came in 1993 when the NTA was enacted. Its provisions allowed Indigenous people to make native title claims in all parts of Australia. Although the 'native title' that was recognized for successful claims did not give the same comprehensive rights as the ALRA did for the Northern Territory, the claim process required some of the same kinds of proof. As for the ALRA, many early recordings, photographs, and films held by archives were sought as evidence. ${ }^{4}$

The amount of material requested for Native Title claims caused serious problems for AIATSIS archive staff. In 1995, the Chair of the Institute Council, Professor Marcia Langton, stated that:

The native title legislation has imposed an excessive workload on our staff because the Institute lacks the resources to deal with the ever-increasing demands for access to our collection. Almost all claimants under the legislation wish to make use of Institute resources....

As a result, a Native Title Research Unit was formed to provide advice and research targeted to the needs of native title clients, and a special position was created within the AIATSIS collections to deal solely with native title requests.

\subsection{Bringing them home: report of the National Inquiry into the Separation of Aboriginal and Torres Strait Islander Children from their families.}

Indigenous people of mixed race who had been removed from their families up until the 1970s are trying to trace their original relatives. Genealogical records, including sound recordings and films, are vitally important for Indigenous researchers. Such materials are so important that the Australian Government has required that all records with Indigenous content held in

4 See Koch, G. 2013 We have the song so we have the land; song and ceremony as proof of ownership in Aboriginal and Torres Strait Islander land claims. http://aiatsis.gov.au/sites/default/files/products/discussion paper/ we-have-the-song-so-we-have-the-land.pdf (accessed 21//0/20 I5)

5 Langton, M. 1995. Chairperson's Message. AIATSIS 94-95 Annual Report. AIATSIS: Canberra. (p2) 
the National Archives of Australia be exempt from disposal orders because they may contain information on family relationships.

\subsection{Indigenous people using the Web to repurpose audiovisual materials from their regions.}

Many Indigenous organisations are starting up their own archives, often producing audiovisual materials that use historical recordings to teach the young people. ${ }^{6}$ Indigenous people in Australia want to see "the old stuff", and they, along with land claimants, have become the major client group at AIATSIS. In AIATSIS, some legacy collections are up to 40-50 years old and had been deposited under vastly different conditions than those now being used by AIATSIS. Many of these conditions have been updated, but some remain problematic.

\subsection{Collecting organisations working to make their Indigenous material more easily accessible.}

For example, the peak organization for libraries in Australasia, National and State Libraries Australasia, has issued a set of objectives to recognize the right of Indigenous people to be informed about relevant collections, to determine use and access to cultural materials, to participate in decision-making processes in managing collections, and to work with libraries to obtain copies. $^{7}$

\section{Three case studies involving legacy collections}

Below are three case studies arising from difficulties raised by problematic legacy collections of Indigenous material held by AIATSIS.

- Paralysis caused by illogical policies

- Extreme closure restrictions

- Unidentified restricted material in an open collection

\section{I Case study I. A circular argument: The Tiwi community visit}

In 2008-2009, the ethnomusicologist Genevieve Campbell described a problematic set of legacy collections held at AIATSIS. The Tiwi people of Bathurst and Melville Islands wanted to gather recordings and films that had been made of their ancestors so that they could rediscover some of their early songs and dances. Several institutions in Canberra held historical collections of Tiwi audiovisual material showing early cultural practices. When the Tiwi contacted AIATSIS for copies, AIATSIS archive policy specified that copies could only be made of collections that had been digitized. The early recordings requested by the Tiwi had not been scheduled for digitization because they had not been appraised for cultural restrictions. The Tiwi who wanted the copies were the very people qualified to assess the material, yet they could not have them sent to their community because of possible sensitive cultural information!

This impasse was solved partially when a delegation of the Tiwi people was able to obtain funding to visit the AIATSIS archive. They listened to the recordings and assured the staff that there were no cultural restrictions. Even so, there were some complications with access conditions that had been set by the people who had made the original recordings. After careful consideration, the Acting Director at AIATSIS gave discretionary permission for copies of some of the collections to be made for some of the Tiwi community, several of whom were children of the people on the tapes.

6 See the Mulka Project at http://www.indigenous.gov.au/the-mulka-project-preserving-yolgnu-culture-and-language (acc. 2/1 I/2015)

7 See the full list of objective with several examples of proactive projects on this site: http://www.nsla.org.au/sites/ www.nsla.org.au/files/publications/NSLA.Indigenous Position statement case studies.pdf (accessed 3/8/20।5) 
This example shows a clash of two different world views- the cultural material owned by members of the Indigenous community who want to reincorporate that knowledge into their performance practice versus the artefact, trapped in a recording that is owned by the collector and managed by an archive. Campbell says that:

In the moment it is recorded the song's ownership shifts and it is only the process of repatriation that enables that ownership to be shifted back. (Campbell 2014:124)

\subsection{Case study 2: Extreme closure restrictions}

From 196I to 1966, a lay missionary and linguist (Collector A) made recordings of approximately 55 hours of language elicitation, narratives and songs from the Bunuba, Bardi, Djawi, Ngarinyin and other Aboriginal peoples from the Kimberley region of Western Australia. He chose extremely stringent access conditions requiring that he be contacted before anyone could either listen to the material on-site at AIATSIS or have copies.

In 1987, staff of the Institute circulated letters, signed by the Deputy Principal, to depositors who had lodged recordings under restricted conditions. The letters urged them to allow people recorded on the tapes, their relatives, speakers of the Aboriginal languages on the tapes and relevant culture centres to have access and/or copies.

Collector A adamantly refused to change the conditions, stating that his deep concern for the welfare of Aboriginal people had prompted him to use the most restrictive access collections possible, and that he needed to maintain personal control of all of his research material. $\mathrm{He}$ had not specified if any changes in access conditions could be made after his death. He felt so strongly about his position that he threatened to take legal action should AIATSIS seek to change his conditions. When he deposited his collections, such access conditions were possible, but, since then, this deposit option has been changed because it caused administrative and ethical difficulties. Thus, because of the extreme access conditions, his collection fell squarely under the category of problematic legacy collections.

When Collector A passed away in 200I, Institute staff contacted his daughter to negotiate a change to the conditions. After several years, she agreed to sign a Transfer of Materials contract that superseded the original restricted conditions, giving responsibility for all of her father's collections, both print and audiovisual, to the Institute. (Koch 20I0:5I)

\subsection{Case study 3: Unidentified restricted material in an open collection}

Another situation arose with Collector B, who, in the early 1960s, made some of the earliest recordings in Cape York of songs, narratives, ceremonial material and language elicitation. Collector B, in his documentation, indicated that some of the songs and discussion could be culturally restricted, but had not filled out a deposit form with the Institute. All of his collections were put under restricted access conditions because it was unclear how to manage it.

Over the years, several researchers had tried to locate him without success, as he was a rather colourful character who did not often have a fixed address. After at least 20 years of trying, a former Institute grantee found him, and explained that he really needed to do something about access conditions. In 1988, he sent a letter to the Audiovisual Archive at the Institute, stating that his collections would be available to anyone, in fact, "the whole world." 8

8 His exact text was: Please place all tapes, films, and other materials deposited in the archive in the most open-toaccess status possible. Anyone, whatever their credentials or lack thereof may use my field materials in any way they fancy with or without acknowledgement. I give the world carte blanche to the legal extent of my right to do so. 
Shortly after that, a group of elders from Cape York visited AIATSIS in order to get copies of recordings and photographs from their area, Lockhart River. Collector B had worked there and had made many recordings with people they had known. There was no problem making copies for the elders, but as they listened to the recordings, they found that some of the songs and discussions, which had not been identified by Collector B as restricted, were to be accessed only by initiated males from Lockhart River. In this case, male staff members from the Institute worked with the elders to provide a cautionary statement. The cataloguing record was updated and now this legacy collection can be managed properly.

\section{Moving towards solutions in handling problematic legacy material}

Last year I began a study on access policies of 28 Australian collecting institutions, Indigenous digital archives and agencies that hold significant collections of Aboriginal and Torres Strait Islander material. I had a particular interest in how they managed sensitive materials.

All of the repositories that I examined had specific policies or protocols about the management of Indigenous material. Nearly all mentioned that they respected Indigenous protocols as set by the communities of people who had provided the information.

Collecting institutions have taken various interim measures to deal with problematic material while they await resourcing to transform it into fully documented and accessible collections. Below are some of the steps taken by the Australian organisations that I surveyed in managing sensitive Indigenous collections, some of which falls under the category of problematic legacy material.

\section{I Cautionary notes}

For example, AIATSIS includes a "Cultural Sensitivity" note on its opening web page. It states:

Aboriginal and Torres Strait Islander people should be aware that this website may contain images, voices, or names of deceased persons in photographs, film, audio recordings or printed material.

Some material may contain terms that reflect authors' views, or those of the period in which the item was written or recorded, but may not be considered appropriate today. These views are not necessarily the views of AIATSIS. While the information may not reflect current understanding, it is provided in an historical context. ${ }^{9}$

Two more cautionary notes appear; one on the page leading to the collections, and another requiring the user to tick a box before they can search the online catalogue.

All Australian State and national archives and libraries have similar cautionary statements that address cultural sensitivity, including possible restrictions. Some of the community-based archives do not allow anyone outside their cultural group to access the databases listing their holdings, and some have restrictions based upon initiatory status and gender.

\subsection{Limiting web access to some audiovisual material}

Libraries and archives maintain a takedown policy for audiovisual materials on the web. AIATSIS only places images on its site that are part of specially created topical online exhibitions and does not allow web-based access to any of its audiovisual collections. 


\subsection{Internal advisory committees and reference groups}

According to their websites, the State Libraries of Queensland, Tasmania, SA, NSW, and the NT indicate that they have Aboriginal Advisory Committees, Councils or other advisory bodies. The National Archives of Australia, and all State Records offices have Indigenous reference groups. Both libraries and archives have Indigenous liaison officers, and the National Film and Sound Archive and AIATSIS have Indigenous staff who advise on day to day matters of access.

\subsection{Proactive joint projects with Indigenous communities}

As legacy collections may not have adequate documentation, cooperative projects with Indigenous communities can benefit all parties. Indigenous people can provide missing information about the collections to the institution and, in turn, can receive copies.

AIATSIS had a Community Access Program that brought people from targeted communities to Canberra to search through collections for items from their areas. Copies, where possible, were made for them to take back to their communities.

Also, the Tiwi people, mentioned earlier in this article, who visited Canberra in 2009 were able to identify the people on the recordings and to advise on access conditions. They visited several collecting institutions in Canberra, including the NFSA, where they gave a free concert. ${ }^{10}$ One of the dances, Wallaby, had been filmed in 1912, and one of the visiting Tiwi men, Walter Kerinaiua, brought the dance to life again before the assembled audience. (Campbell 20 I4: I 19-I20)

In turn, the Tiwi received copies of the recordings, including the 1912 film that inspired Walter's performance in Canberra. Campbell describes benefits to the Tiwi resulting from this return as increasing respect for the singers of the past and rediscovering song traditions. (Campbell 2014:117-II8)

\section{Some projects outside Australia}

\section{I Hidden collections registry}

The Council on Library and Information Resources was given funding by the Andrew Mellon Foundation to establish a Hidden Collections Registry" . These fall into my definition of legacy collections. Organisations were invited to nominate collections that were important to scholarship but did not have enough documentation to enable discovery. Grants were awarded to organisations that developed innovative and efficient approaches to describing rare collections, and it was understood that they would digitize the collections. Of I 29 cataloguing grants, totaling over $\$ 27.5$ million US, 103 contained significant collections of audio.

\subsection{Endangered Archives Programme}

Since 2004, The Arcadia Fund ${ }^{12}$ has supported the Endangered Archives Programme at the British Library. This scheme provides grants to preserve archival material in danger of loss. These are targeted towards historical material from countries or regions where there is limited funding to save important collections. Dr. Tjeerd de Graaf, who spoke at the last IASA conference that was held in Paris in 1998, received a grant to bring together metadata and recordings of endangered Arctic languages. Other examples are preserving analog recordings in the Solomon Islands, digitizing the music of Burma recordings, and various digitization projects for photographic archives. The IASA website lists information on the scheme.

10 http://nfsa.gov.au/site media/uploads/file/2010/I I/03/09-10-Annual-Report.pdf, p.50 (acc. 4/7/20 I5)

I http://www.clir.org/hiddencollections/registry\#c|2=all\&b start=0 (acc. 9/|2/20|4)

12 http://www.bl.uk/press-releases/20 I5/february/endangered-archives-programme-10-years (acc. 2/I I/20 I5) 


\subsection{Historical Archives Program}

The Wenner-Gren Foundation offers grants through its Historical Archives Program (HAP) ${ }^{13}$ to enable established scholars or their heirs to prepare and to transfer their collections of anthropological research materials to appropriate archival institutions. This scheme serves more to ensure that the collections will not become problematic in the future rather than dealing with existing ones.

\section{The importance of advocacy}

Tragically there are few sources of funding available to help get problematic legacy collections into a usable form. IASA, with its connections to international archival, information management, and media organisations and their peak body, the Co-ordinating Council of Audiovisual Archives Associations (CCAAA), has publicized various funding schemes relevant to archives. As Ray Edmondson has said, we need a coordinated program of advocacy for financial assistance to audiovisual collections. ${ }^{14}$

Although they pose special dilemmas, problematic legacy collections often hold invaluable cultural material, as I have shown. If they are lost, an important part of our history will go with them.

\section{References}

Campbell, Genevieve." "Song as Artefact:The Reclaiming of Song Recordings Empowering Indigenous Stakeholders and the Recordings Themselves." In Circulating Cultures: Exchanges of Australian Indigenous Music, Dance and Media, edited by Amanda Harris, 108-128. Canberra, Australia:ANU Press, 2014.

Greene, Mark and Dennis Meissner.“More Product, Less Process: Revamping Traditional Archival Processing." The American Archivist 68, no. 2 (September 2005): 208-63.

Koch, Grace. "Ethics and Research: Dilemmas Raised in Managing Research Collections of Aboriginal and Torres Strait Islander Materials." Australian Aboriginal Studies, 2 (20 I0): 48-59.

Koch, Grace. "We Have the Song so We Have the Land; Song and Ceremony as Proof of Ownership in Aboriginal and Torres Strait Islander Land Claims." Discussion Paper. Canberra, Australia:Australian Institute of Aboriginal and Torres Strait Islander Studies, 20I3. http://aiatsis.gov.au/sites/default/files/products/discussion_paper/wehave-the-song-so-we-have-the-land.pdf.

Langton. Marcia. "Chairman's Report" in Report of the Australian Institute of Aboriginal and Torres Strait Islander Studies 1994-1995." Canberra, Australia:Australian Institute of Aboriginal and Torres Strait Islander Studies.

Laszlo, Krysztina. "Ethnographic Archives and Cultural Property." Archivaria 6I, (2006): 300308.

Lyons, Bertram, Rebecca Chandler, and Chris Lacinak. "Quantifying the Need:A Survey of Existing Sound Recordings in Collections in the United States.” Brooklyn, New York:AVPreserve, 20 I5. http://www.avpreserve.com/wp-content/uploads/20I5/05/ QuantifyingTheNeed.pdf. (acc 10/07/2015)

13 http://www.wennergren.org/programs/historical-archives-program-hap

14 http://unesdoc.unesco.org/images/0013/001364//36477e.pdf 
National Inquiry into the Separation of Aboriginal and Torres Strait Islander Children from their families. "Bringing Them Home : Report of the National Inquiry into the Separation of Aboriginal and Torres Strait Islander Children from Their Families (Australia)." Sydney: Human Rights and Equal Opportunity Commission, 1997. http:// www.austlii.edu.au/au/other/IndigLRes/stolen/prelim.html.

Proutskova, Paulina and Janet Topp-Fargion. "Data Infrastructure for Ethnomusicological Archives - Current Situation and Future Perspectives.” IASA Journal 3I, (July 2008): 45-58. 